\title{
Gas Turbine Blade made of FG75 -Investment Casting Technology for Complex, Hollow, Fibre-Reinforced NiAl-Components
}

\author{
Foundry Institute, S. Hollad, C. Dahmen, A. Bührig-Polaczek \\ Foundry Institute of the RWTH Aachen University; Intzestreet 5, 52072 Aachen, Germany
}

Keywords: NiAl-investment casting, superalloy FG75, fibre-reinforced NiAl-components

\begin{abstract}
The collaborative research centre SFB 561 "Thermal highresistant open-pore and cooled multilayer systems for hybrid power stations" is aimed at enhancing the total efficiency of hybrid power stations from the current level of $58 \%$ to approx. $65 \%$. This requires the realization of turbine entering temperatures of $1,400^{\circ} \mathrm{C}$ (ISO) in a gas turbine, and involves both the investigation of new materials and production processes as well as new kind of layered components for transpiration cooling. A main focus in foundry technology is the manufacture of components from highly temperature-resistant $\mathrm{NiAl}$ and $\mathrm{NiAl}$ composites.

The development of a casting technology for technically interesting NiAl-alloys is part of the Foundry-Institute subproject "Casting Technology". Its aim is the development of a scientific and technological basis for the manufacture of effusion-cooled gas turbine blades. Due to their high melting temperatures of approximately $1,640^{\circ} \mathrm{C}$, their high thermal conductivity and high oxidation resistance at elevated temperatures, $\mathrm{NiAl}$-alloys are well suited as a substitute for superalloys, amongst others, in combustion chamber linings and turbine blades.
\end{abstract}

\section{Introduction}

It is the aim of the development works in the area of pouring technology for the innovative concepts of the SFB 561 to produce components from NiAl and NiAl-composites. The components desired as installation ready shall be established near net shape and in a quality relevant to technical application. New materials and manufacturing processes will be treated as well as new components in sandwich layer style for a transpiration cooling. Basic examinations to shell mould ceramics for the investment casting of $\mathrm{NiAl}$ base alloys, to the testing of chemically resistant core ceramics and the development of the processing technology for the pouring technical production of test pieces as well as first model components, were carried out. NiAl base alloys show high melting points (approx. $1,640^{\circ} \mathrm{C}$ ) and react in an unwanted way with the conventional shell mould ceramics. A special difficulty in the pouring technical production of components resulted from the characteristic ductile brittle transition of the alloys during the solid solidification by e.g. $1,000^{\circ} \mathrm{C}$ to $700^{\circ} \mathrm{C}$. In pouring tests, pore poor solid and hollow test pieces free of cracks were produced using $\mathrm{SiO}_{2}$ free binders. A parameter window was ascertained to be reliable $\mathrm{NiAl}$ pourings with reproducible qualities. The required working steps were examined, respectively developed, with regard to component size, core production, pouring of complex and thin-wall geometries as well as long fibre reinforcement, and comprehended as a process demonstrator in numerical simulation and real production.

\section{Representation of the previous development}

The work and results from the work scope pouring technique are introduced by complex NiAl components, long fibre reinforcement of $\mathrm{NiAl}$ components, simulation of the pouring processes and components and development of the production demonstrator, respectively turbine vane cut-out. The pouring tests were carried out in a Bridgman furnace due to previous results. The excellent options for temperature control were used here with simultaneous pouring under protective gas. In addition, in sequence of operations and method the work carried out obtained this one results be described. For the necessarily understanding on the whole further solution trials which are not pursued are justified and introduced too.

\section{Pouring technical production of complex components}

To continue the developments and knowledge in the direction of the production of turbine blades consistently, the main emphasis of the work was on the development of the pouring technology for complex and effortful geometries as they are represented today, chilled turbine blades. To accomplish this goal after the provision of the shell mould systematic and the principle investment casting technology, the reproducible, pouring technical production of complex NiAl components from the alloy FG75 with the composition of $45 \mathrm{at}-\% \mathrm{Ni}, 45 \mathrm{at}-\% \mathrm{Al}, 7.5 \mathrm{at}-\% \mathrm{Cr}$ and $2.5 \mathrm{at}-\% \mathrm{Ta}$ must be examined. For this assignment of the process steps to the application with complex geometries, working steps which were more parallel and coordinated were necessary:

a. Development of further core materials On the exposition of complex geometries which could not produced by machining processing of core material themselves. For this purpose, these corresponding core materials must be compressible or castable.

b. Reduction of the possible wall thicknesses,

Modern gas turbine vanes are nowadays inevitably chilled on the inside for reasons of the efficiency and therefore have wall thicknesses of less than $2 \mathrm{~mm}$. With the created NiAl investment casting base technology, such wall thicknesses were impossible because of strong crack formation.

c. Increase in the possible, castable component sizes, The increase in the possible component sizes from small principle samples to considerable samples- and component sizes was indispensable for the investigation of the NiAl-pouring technology for gas turbine vanes, since the known problems and difficulties are contrary to an enlargement of geometries in the pouring of $\mathrm{NiAl}$ alloys.

d. Geometry variations

In the context of these process and material developments, several suitable specimen geometries were developed for the pouring experiments. For these, a multiplicity of factors had to be taken into account, just like for the simple specimen geometries, like the 
flow velocities in the shell mould, mould filling, filling times, and feeding behaviours, mechanical interactions between the component, specification and removal of cores. These new test pieces are introduced in the following context of the examinations and pouring experiments.

e. Core material development

It was the aim of the core material development to find additional core materials which make it possible to represent complicated geometries of cores in the pouring of $\mathrm{NiAl}$ alloys. The requirements on these core materials were:

- Investment casting technical suitability of the cores for the $\mathrm{NiAl}$ investment casting process with regard to temperatures, mechanical loads etc.

- No surface reactions or defects,

- Form filling in dependence on the wall thickness,

- Free geometry design, i.e. the core material can be pressed or cast,

- Compressibility for the avoidance of crack formation in the $\mathrm{NiAl}$ components during solidification and cooling

The focus of the tests lies on the interactions between the selected core materials and the alloy FG75. These are the investment casting technical suitability of the cores, the surface reactions of the cores, or the surface errors resulting from them and the form filling in dependence on the wall thickness.

Four different central geometries were designed for the examinations. With these geometries, it was possible to realize different wall thicknesses of $6 \mathrm{~mm}, 4 \mathrm{~mm}$ and $2 \mathrm{~mm}$ as well as a relieving wall thickness from $8 \mathrm{~mm}$ to $4 \mathrm{~mm}$. Therefore, these geometries could also be used to exanimate the minimum possible wall thickness, as described below.

The examined core materials were different, fire-proof, $\mathrm{SiO}_{2}$ free concretes. Such concretes are mixed with water and brought in form by pouring. The examined core materials achieved compressive strengths of 20-70MPa by hardening / drying which permits the usual investment casting handling. A following burning at $1,450^{\circ} \mathrm{C}$ gives the cores a sufficient strength for high temperature use. After the firing process, a maximum compressive strengths of $110 \mathrm{MPa}$ could be achieved. Further data for the most important core materials, like composition of the core materials, chemical and mechanical properties, are found in Table I.

Silicone forms were produced with the aid of aluminum master models for the production of the cores. The core materials were mixed in different mixing ratios with water. Furthermore, the cores were treated differently after removal to yield a broad spectrum of cores so that a suitable core material could be found. So several series of experiments were not burned, others were burned with the below mentioned burning programme and in turn others were treated the front layer-slurry of the shell mould system before the firing. Of these variations, 12 investment casting capable core versions were produced. Defects leading to the exclusion were core breakage or surface defects.

After the core production tests, the cores which classified as suitable were extrusion-coated with a wax model and assembled to form a test setup. The pouring tests of the different sets with different pouring parameters, like shell mould temperature and pouring temperature, led to results concerning the interactions with the FG75 surface, the crack inclination of the cast components and the removability of the cores. Using these examinations, a suitable core material could be found. The material 1801 is suitable to establish complex cores by casting. This material shows sufficient mechanical properties to withstand the manufacturing process of FG75 components and have the necessary compressibility of $20 \mathrm{MPa}$ simultaneously with a compressive strength to get $\mathrm{NiAl}$ components free of cracks during the casting. Also, the necessary chemical resistance with regard to the very reactive FG75 melt could be guaranteed.

Table I: Survey of the most important core materials

\begin{tabular}{|c|c|c|c|c|}
\hline \multicolumn{2}{|l|}{ Core Materials } & 1801 & 1804 & 1805 \\
\hline \multicolumn{2}{|l|}{ raw material base } & \multicolumn{2}{|c|}{ corundum } & spinel \\
\hline \multicolumn{2}{|c|}{ max. application temperature $\left[{ }^{\circ} \mathrm{C}\right]$} & 1800 & 1800 & 1800 \\
\hline \multirow{5}{*}{$\begin{array}{c}\text { relevant properties } \\
{[\%]}\end{array}$} & $\mathrm{Al}_{2} \mathrm{O}_{3}$ & 98 & 98.5 & 88 \\
\hline & $\mathrm{SiO}_{2}$ & - & - & - \\
\hline & $\mathrm{Fe}_{2} \mathrm{O}_{3}$ & - & 0.1 & 0.2 \\
\hline & $\mathrm{CaO}$ & 1.3 & - & - \\
\hline & $\mathrm{MgO}$ & - & - & 10 \\
\hline \multicolumn{2}{|c|}{ strength after drying at $110^{\circ} \mathrm{C}[\mathrm{MPa}]$} & 20 & 70 & 50 \\
\hline \multicolumn{2}{|l|}{ gain size $[\mathrm{mm}]$} & $<6$ & $<6$ & $<6$ \\
\hline \multirow{3}{*}{$\begin{array}{l}\text { heat conductivity } \\
{[\mathrm{W} / \mathrm{mK}]}\end{array}$} & $600^{\circ} \mathrm{C}$ & 2.81 & 2.80 & \\
\hline & $1,000^{\circ} \mathrm{C}$ & 2.85 & 2.84 & \\
\hline & $1,300^{\circ} \mathrm{C}$ & 3.10 & 3.12 & \\
\hline \multicolumn{2}{|c|}{$\begin{array}{l}\text { linear heat expansion coefficient } \\
{\left[10^{-7} \mathrm{~K}^{-1}\right]\left(20-1000^{\circ} \mathrm{C}\right)}\end{array}$} & 80 & 80 & \\
\hline \multirow{2}{*}{$\begin{array}{l}\text { compressiv strength } \\
\text { after } 5 \mathrm{~h} \text { at }\end{array}$} & $1400^{\circ} \mathrm{C}$ & 38 & 110 & 110 \\
\hline & $1600^{\circ} \mathrm{C}$ & 30 & 145 & 150 \\
\hline \multirow{2}{*}{$\begin{array}{l}\text { constant linear } \\
\text { elongation }[\%] \text { after }\end{array}$} & drying $110^{\circ} \mathrm{C}$ & \pm 0 & \pm 0 & \pm 0 \\
\hline & firing $1600^{\circ} \mathrm{C}$ & -0.40 & -0.20 & -0.57 \\
\hline
\end{tabular}

Examinations of the wall strength reduction

Parallel to the examinations tests of the core material development, pouring experiments were carried out to determine the minimum wall thickness. It was the aim to realize components with thin wall thicknesses and simultaneously to find out the minimum possible wall thickness. Therefore, flat, curved and hollow geometries were examined. The advantage of flat geometries is the delimitation of possible influence factors. So core materials and tension formation in hollow components do not play a role in such geometries, for example. On the other hand, curved or really hollow components come considerably closer to the desired reality. Geometries with constant wall thicknesses and with conical wall crosscuts were examined for the hollow components.

The first test series were carried out with geometries introduced in the previous period. These geometries permitted good control of the filling process and the crack formation difficulties, the two main difficulties at the production of $\mathrm{NiAl}$ components with a low wall thickness. These pouring experiments were supported by pouring-, solidification- and residual stress simulations which made a clear reduction of the experimental expense possible. Particularly with regard to the filling process which cannot be comprehended in the reality and the formation of the residual stress, a large amount of expertises were obtained concerning the gating geometries and the process flow. With those expertises, progresses in the development are justified. These simulations are explained more precisely in the following chapter "numerical simulation." 
First attempts showed that these hollow geometries had an unacceptable form filling. Components then could, however, be realized by a numerical simulation the form filling process with gating optimization following on this and simultaneous customization of the pouring parameters, with low wall thicknesses to $2 \mathrm{~mm}$. At the geometry with $2 \mathrm{~mm}$ wall thickness the filling behaviour was very problematically. The areas of the parts not flowed out, were also sensible for cracking. Such cold shuts appeared only at the castings with $2 \mathrm{~mm}$ wall thickness. A too fast heat removal over the shell mould manifests particularly at these thin wall thicknesses by an early solidification. To avoid cracks and cold shuts the preheating temperature of the shell mould was set gradually from $1300^{\circ} \mathrm{C}$ to $1450^{\circ} \mathrm{C}$.

This higher shell mould temperature causes a stronger grain growth, though. At the current, lower wall thicknesses, this only had to be expected to a lesser extent, though, and the problem thus only is subordinate. However, the wall thickness could very successfully be lowered.

Metallographic examinations then showed too that the hollow samples almost do not show any porosity in the relevant areas. However, porosities could only be found in the gating and feeding system which points to a good feeding behaviour, Figure 1 .

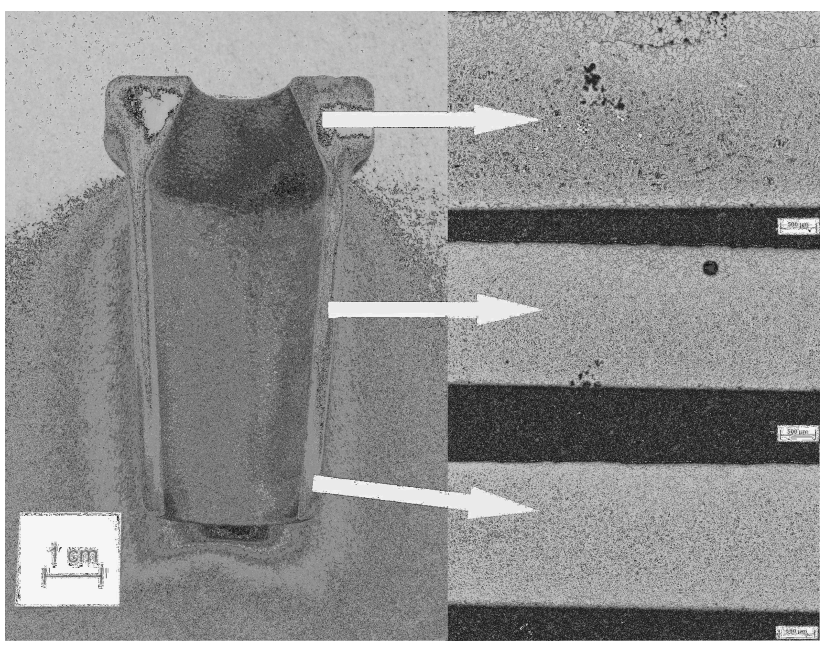

Figure 1: Micrograph with a 25-fold enlargement of the cast component with $4 \mathrm{~mm}$ wall thickness, porosities in the gating and almost poreless structure in the real sample

Flat and very thin specimen geometries were examined in pouring experiments for the pure flowing ability analysis, as represented in Figure 2. This geometry excluded the influence of the core materials and -geometries on the pouring result. Here it could be noticed that the contraction disability of the pouring by the shell mould has an additional influence on the crack formation in the pouring. Only the shrinking hindrance by friction on the shell mould can therefore lead to crack formation during the cooling. This must be taken into account by a careful front layer construction. A sufficiently high viscosity of the front layer slurry prevents snap through of the sanding particles and yields a slippery shell mould surface, Figure 3 [1]. Subsequently, based on these results, a small and very thin-walled shovel geometry was successfully poured. This geometry is found in the chapter "geometry variations".

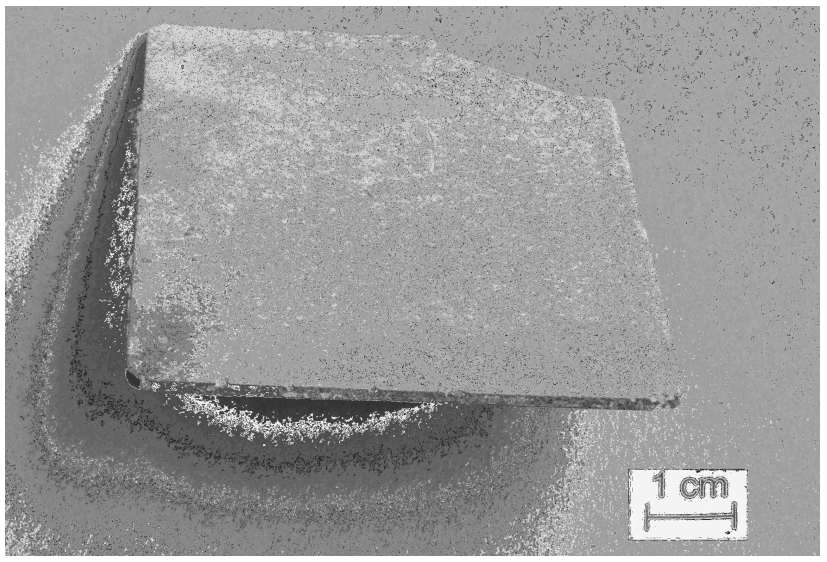

Figure 2: $\mathrm{NiAl}$ (FG75) sample with a wall thickness of $1.5 \mathrm{~mm}$

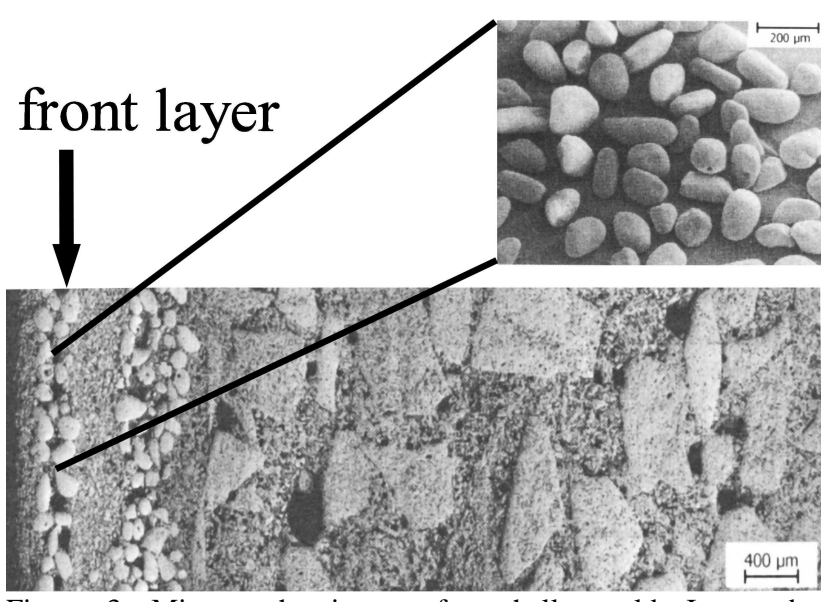

Figure 3: Micrograph picture of a shell mould. It can be recognized well that the round grains of the front layer have not penetrated the front layer slurry [1].

\section{Increase of the component size to realistic component dimensions}

The enlargement of sample and component geometries involves an increase in the known problems on the investment casting technology for NiAl base alloys:

- In complete flowing out, the form cavity must be reached without raising the shell mould temperature considerably since this leads to a rough mircostructure.

- Crack formation compensation must be reached also on expansive components, even if on these, the contraction disability by the shell mould surface and the crack formation probability increases.

- An inaccurate production by increased production tolerances must be prevented. By softening of the shell mould and a significant rise in the hydrostatic pressure, the inclination towards a mechanical expanding of the shell mould increases considerably.

The starting point for the examinations was flat, plate-shaped samples with measurements of $50 * 50 * 5 \mathrm{~mm}$.

Flat geometry enables simplified checking of the production tolerances and comparison with bigger plates. After the pouring of these small plate geometries deviations in the wall thickness of at most $0.5 \mathrm{~mm}$ arise.

Following this, samples with the measurements of $200 * 90 * 5 \mathrm{~mm}$ were examined. In advance of these pouring tests, corresponding 
simulations had also been carried out; see chapter "numerical simulations". The following test plates show visually clear differences compared with smaller trials already before deforming. Above the whole crosscut, all flat plates show thicker wall thicknesses than scheduled. As assumed, a softening of the shell mould due to the high process temperatures can be observed. In consequence, the shell mould yields under the hydrostatic pressure of the NiAl melt in the area of the sample and the sprue. The sprue expansion is justified by the weakening of the round cross-section of the plate gatings. A measure inaccuracy arises in the context of these great geometries. The deviations can no longer appropriately be considered in the wax model.

Therefore, different reinforcement alternatives for the shell mould were examined. It had to be taken into account that an extremely stiff shell mould leads inevitably to crack formation during the cooling of the brittle ductile transition. This was confirmed in the following pouring experiments too.

A support between the plates led to successful trails. This does not change the developed sandwich construction of the shell mould system. Such a support limits, however, beating out the shell mould over the sample. As a result, a considerable reduction of the measure inaccuracy can be established. Table II shows that maximum deviations of only $0.70 \mathrm{~mm}$ can appear with this development.

It can therefore be observed, based on these tests, that the shell mould technology is usable also for samples or components scaled substantially more generously. A form filling can be reached without problems with a corresponding gating technology. The crack formation in dependence of the shell mould design, that means front layer roughness and sandwich construction, is avoided and acceptable production tolerances can be reached simultaneously.

Table II: Deviations at different samples respectively shell mould sizes.

\begin{tabular}{|c|c|c|c|}
\hline $\begin{array}{c}\text { max. } \\
\text { deviation } \\
\text { at the }\end{array}$ & $\begin{array}{c}\text { plate geomtry } \\
(50 * 50 * 5 \mathrm{~mm})\end{array}$ & $\begin{array}{c}\text { plate geomtry } \\
(200 * 90 * 5 \mathrm{~mm})\end{array}$ & $\begin{array}{c}\text { plate geomtry } \\
(200 * 90 * 5 \mathrm{~mm}) \\
\text { with optimized } \\
\text { shell mould }\end{array}$ \\
\hline $\begin{array}{c}\text { border of } \\
\text { the plate }\end{array}$ & 0.25 & 1.00 & 0.30 \\
\hline $\begin{array}{l}\text { centre of } \\
\text { the plate }\end{array}$ & 0.50 & 3.30 & 0.70 \\
\hline
\end{tabular}

\section{Geometry variations}

A number of further samples and components were developed, poured and examined. On the one hand, partner projects were supplied for further examinations and process developments. On the other hand, special geometries were necessary for detailed examinations of the investment casting process. With the specimen geometries introduced above, not all questions could be clarified completely. Further geometries permitted pouring experiments with well-limited process changes and a relatively low number of influential factors. As far as possible, the requirements of the extraditable samples and the samples for the process analysis were fulfilled with the same specimen geometry. As starting point for any examination, the heavy and /or hollow samples (two different sample geometries) represented in Figure 4 were applied. These samples were used for the development of the principle pouring technology. An excellent comparability is given to the results through the collected experience with these samples which therefore are well suited for pouring experiments. Until now, the shovel geometry in Figure 5 has only been cast for pouring experiments. Furthermore, in the near future, these shovel geometry will be delivered to further subprojects (heat isolation layers, fibre coating and fine drillings) for additional tests.

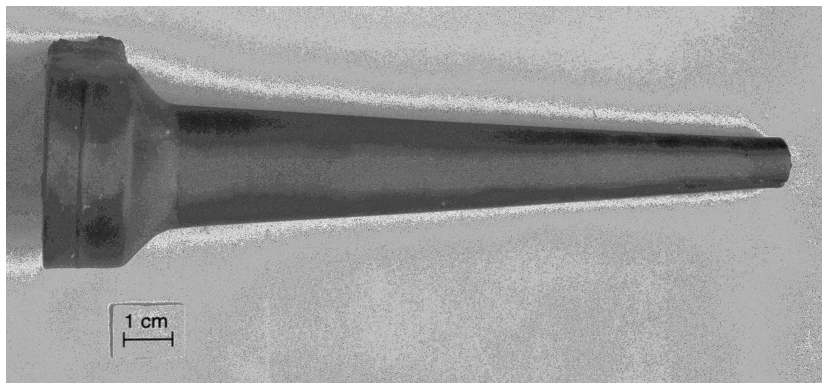

Figure 4: Conical hollow specimen configuration with gating head on the left side

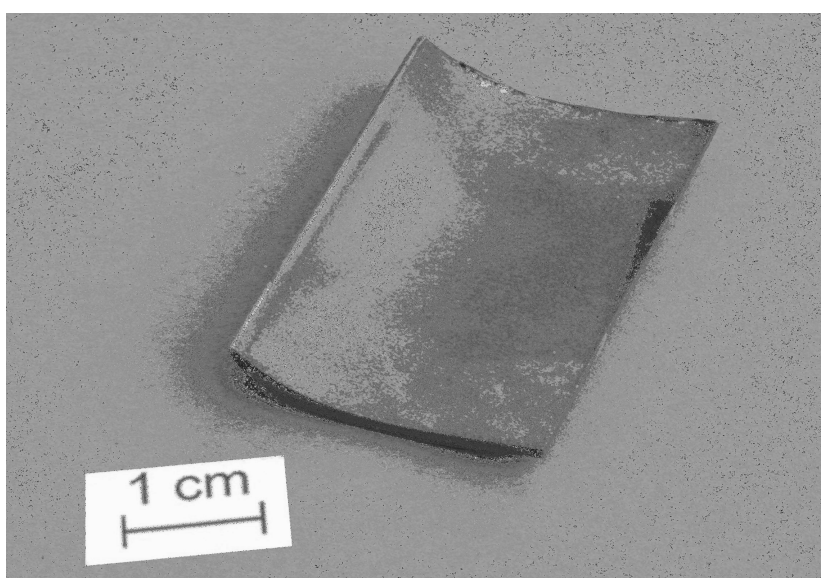

Figure 5: Turbine vane part (geometry of a small aeronautic turbine)

\section{Pouring technical production of long fibre reinforced NiAl components}

The characteristic in the construction of the turbine blades planned in the SFB 561 is the load take-over by a long fibre reinforced core made of $\mathrm{Al}_{2} \mathrm{O}_{3}$ fibres and a polycrystalline $\mathrm{NiAl}$ matrix. In the subprojects "fibre coating" and "long time constant fibre reinforcements", long fibre reinforced composite material samples are established and moulded-in with NiAl (FG75) for the production of test pieces and parts. After that, in the subprojects "heat isolation layers" and "fine drillings", the coating and drilling of the cooling air pores follow. The principle with samples of the most important production steps is found in Figure 6.

The principle sequence of the mould-in processes then subdivides itself as follows: Shell mould production, fixing of the fibre reinforced preforms in the shell mould, pouring under protective gas and controlled heating and cooling conditions. The exact pouring parameters are [5], [5]:

- Pouring temperature $\mathrm{T}_{\mathrm{S}}: 1,700^{\circ} \mathrm{C} \pm 20^{\circ} \mathrm{C}$,

- Preheating temperature of the shell mould $\mathrm{T}_{\mathrm{F}}: 1,300^{\circ} \mathrm{C}$,

- Cooling rate above $1,100^{\circ} \mathrm{C}: 9 \mathrm{~K} / \mathrm{min}$,

- Cooling rate below $1,100^{\circ} \mathrm{C}: 2.5 \mathrm{~K} / \mathrm{min}$.

The fibre compound samples of monocrystalline $\mathrm{Al}_{2} \mathrm{O}_{3}$ fibres shown in Figure 6 under item 2 are poured in a NiAl matrix. The 
developed sample design on the left side in Figure 7 is well suitable for the principle examination of transfusing $\mathrm{NiAl}$ composite material samples containing fibre. Pouring experiments and simulations have to be well understood by the simple structure. Very good practical results and excellent agreement of these results therefore arise with the numerical simulations.
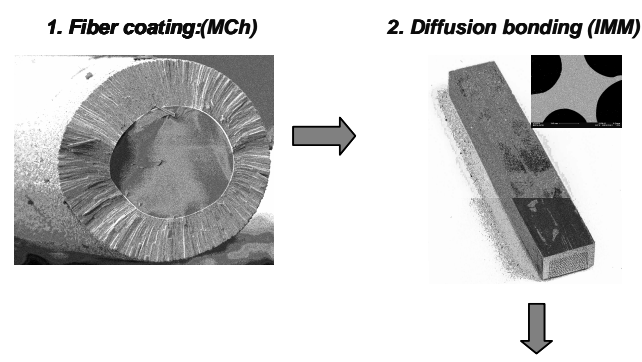

3.Coating (IOT) and

4. Embedded casting in NiAlalloy (NiAl-2.5Ta-7.5Cr) (GI) microdrilling (LLT)
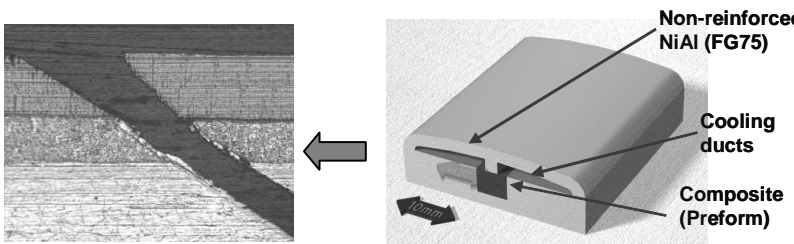

Figure 6: Principle process of the composite material and material compound production for gas turbine vanes from $\mathrm{NiAl}$ [10].

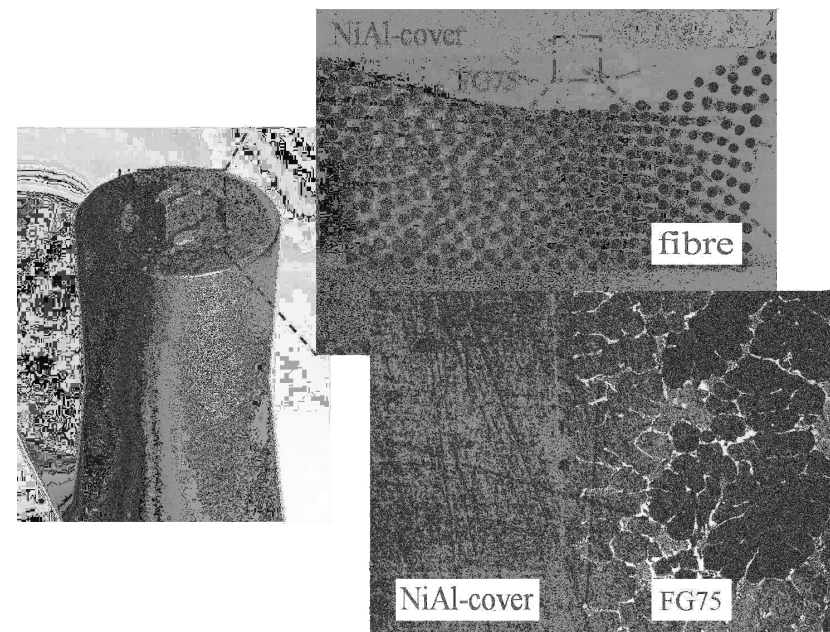

Figure 7: Specimen geometry for the examination of the fibre reinforcements by means of transfusing with the dedicated micrograph pictures. The defect-free boundary layer can be recognized well between the NiAl cover of the fibre preforms and FG75 [7].

In the simulation of the solidification process, it was shown that on the one hand the liquidus temperature $\left(1640^{\circ} \mathrm{C}\right)$ both at the surface and within the fibre compound is not achieved, but that the solidus temperature $\left(1,480^{\circ} \mathrm{C}\right)$ on the other hand is exceeded A maximum temperature of just over $1,600^{\circ} \mathrm{C}$ is reached, and with that, the solidus-/ liquidus clearance. A good connection of the composite to the surrounding $\mathrm{NiAl}$ (FG75) should be reached with that [7], [8]. These results achieved by the simulation were also verified by micrograph pictures of the real pouring, Figure 7 It was recognized very well that transfusing the fibre compound the surface has been surface-fused, but that the composite itself has not melted, Figure 7. This led to a very good connection between the fibre compound and the matrix made of $\mathrm{NiAl}$ (FG75), Figure 7. It is also positive that there are no changes in the fibre matrix structure. Additionaly, the pourings are crack- and pore free and for that reason in the totality extremely promising. Closer examinations of the preform and interface structure are found in the subproject "long term constant fibre reinforcements".

Subsequent to these tests, due to the very good results and the small number of available fibre set, further specimen geometries were neglected in favor of the shovel-like production demonstrator, Figure 6 under item 4.

Technical pouring production of a turbine vane part

The aim was to manufacture a turbine vane cut-out, on which it is possible to show all production steps, like coating of the fibres, squeeze the fibres as preform, technical pouring production, inclusive of transfusing the fibres, as well as superimposing the heat isolation layer and fine drilling of the cooling air fields. To carry out the production of such a concept, an application -similar test piece had to be developed in the run-up. This test piece should replicate the design of a turbine blade. For this production demonstrator, a suitable geometry to make testing of the individual production steps possible was designed in cooperation with the other subprojects.

\section{Development of the component design}

The development of the component design was determined by the most producible size of the fibre preforms of approx. $4 \times 7 \times$ $40 \mathrm{~mm}$ and the specifications of a wall thickness of no more than $2 \mathrm{~mm}$ and the cooling air duct height of also $2 \mathrm{~mm}$. Furthermore, the fibre preforms were to be used at different heights. In accordance with this example, the following design was developed, Figure 8 .

This design has the specified low wall thicknesses of $2 \mathrm{~mm}$. Furthermore, it has a curved surface with different radii. Conditions and geometries are brought closer to that of a turbine vane part. The fibre reinforced preform becomes moulded-in partial and is cast on in the upper area the bar.

\section{Fibre integration}

Integration of the fibres is established by inserting the preforms into the template. Fixing brands were provided for it in the matrix. After the coating with wax, the preform juts protrurde from the model. Through this, subsequent fixing in the shell mould is ensured after dewaxing, Figure 8. Due to the scarcity of fibres, dummy preforms were manufactured using unamplified FG75 for first attempts.

\section{Core integration}

Two possibilities were examined for the core integration. Manufacturing the cores and inserting them into the template before coating with wax or filling the cavities after the production of the wax model. For the second method, it is necessary to use initially metal cores which can be removed later to form the cavities of the model, as in Figure 8. This method will therefore be no longer feasible at more complex central geometries. 


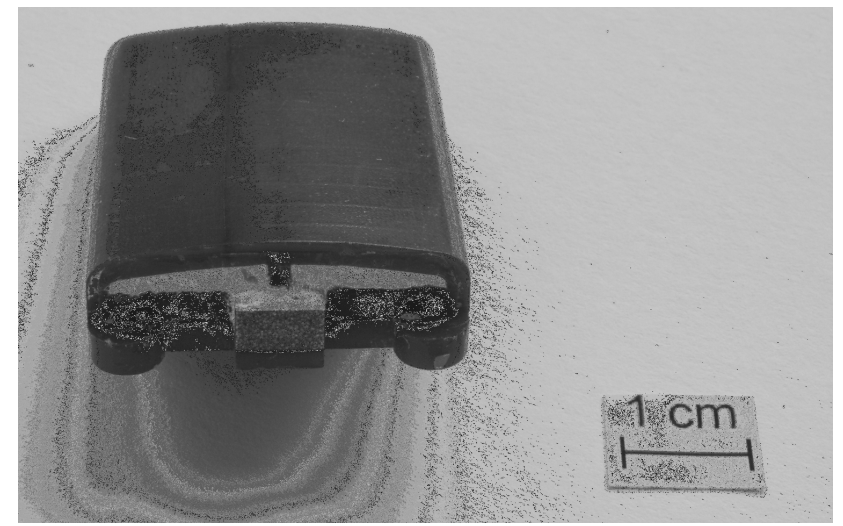

Figure 8: Wax model with dummy preform and ceramic cores Sample production

The first pourings of the demonstrator were carried out without preforms to test the pouring parameters developed by means of the simulation. Furthermore, the suitability of the gating and ingate system could be examined in this way. In addition, experience were gained regarding the two methods for the core integration described above. After these experiments, further tests were carried out both with fibre preforms and the aforementioned dummy preforms. In chapter "results", a finished samples of the demonstrator with fibre preform is shown.

\section{Numerical simulation}

Numerical simulations were carried out for the support of the pouring technology development around a suitable lay-out of ingate system; it was possible to execute more simply and faster the pouring temperature and the shell mould temperature, etc.. The software packages MAGMAsoft and CASTS can carry out initial tests of special experimental situations and determine their suitability and optimisation.

\section{Development of the pouring technology supported numerical simulation}

For the execution of numerical simulations of form filling procedures, solidification events and internal stresses with the programmes MAGMAsoft and CASTS, knowledge of numerous thermal physical data is required. Most must be determined temperature-dependently [6]. The data sets are listed in the following:

Thermal physical data of the alloy

- Solidus-liquidus interval $\left(\mathrm{T}_{\mathrm{L}}-\mathrm{T}_{\mathrm{S}}\right)$

- Latent heat L

- Feeding ability

- Heat conductivity $\lambda$

- Density $\rho$

- Heat capacity $c_{p}$

- Fraction solid $\mathrm{f}_{\mathrm{s}}$ in the liquidus-solidus interval

- Thermal expansion coefficient $\alpha$

- Viscosity $\eta$

Heat-transfer coefficient $\alpha$

- Heat-transfer coefficient between alloy and shell mould

- Heat-transfer coefficient between alloy and surrounding medium

- Heat-transfer coefficient between shell mould and surrounding medium

Thermal physical data of the shell mould
- Heat conductivity $\lambda$

- Pensity $\rho$

- Heat capacity cp

- Thermal expansion coefficient $\alpha$

Mechanical properties of the alloy

- Young's modulus E

- Poisson's ratio $v$

- $\quad$ Yield point $\sigma_{0.2}$

Mechanical properties of the shell mould

- Young's modulus E

- Poisson's ratio $v$

- Yield point $\sigma_{0.2}$

For the calculation of radiation losses and natural convection cooling in CASTS

- Spectral emission coefficient $\varepsilon$ (for the calculation of the free radiation)

- If necessary, surface issue coefficient (for the calculation of the view factor radiation)

- Heat transfer coefficient (for the simulation of gas refrigeration)

Due to the innovative character, the low examination depth and the rare application also in the research, only some vertices of the thermal physical and mechanical data sets really are confirmed for the used NiAl materials. In the literature research, it has to be taken into accounts that in $\mathrm{NiAl}$ materials, small changes in the alloy composition already cause considerable consequences regarding the thermal physical and mechanical data properties. Therefore similar alloys may not be taken offhand.

The current project, drew on an improved material data set based on earlier works on corresponding NiAl base alloys. Given an additional measuring at the Institute of Energy Research, Jülich the Young's modulus course was examined with regard to the temperature. Furthermore Tsol, Tliq, fs and $\mathrm{cp}$ were calculated with the help of the software Thermo-Calc with the alloy composition.

As shell mould material, until now, data from the databases by MAGMAsoft and CASTS was chosen for $\mathrm{Al}_{2} \mathrm{O}_{3}$ which is also a base material of the shell mould actually used. The values in MAGMAdata are, however, based on the standard of pure $\mathrm{Al}_{2} \mathrm{O}_{3}$ sand. Seeing as these mechanical characteristic conditions, which have been exposed as too low, take influence on the development of tensions during the solidification, a new data set should be carried out.

Due to the discrepancies between the data set available in the foundry institute for FG75 and the data from external references, an adaptation of the data set to this partly more reliable data seemed necessary. Particularly the displacements of the curves of the typical course appearing in several data series at about $350^{\circ} \mathrm{C}$ to a lower temperature range suggested defects of the available data set.

The following parameters were taken or adapted:

The solidus-liquidus interval of the available data set is within the same range of the bibliographical references and the calculations. It was therefore left at $1,480^{\circ} \mathrm{C}-1,640^{\circ} \mathrm{C}$.

The latent heat was kept after calculations with Thermo-Calc and comparisons with other metals with a value of $242 \mathrm{~kJ} / \mathrm{kg}$.

The data set for the heat conductivity $\boldsymbol{\lambda}$ already lay in the available data set within a correct range. However, the course was brought closer to IN939 and taken from the values in [4]. In the 
new data set, the heat conductivity for the solidified material lies at $70-80 \mathrm{~W} / \mathrm{mK}$.

The density $\rho$ corresponds with the details in external sources and is kept unchanged at approx. $6 \mathrm{~g} / \mathrm{cm}^{3}$.

The course of the heat capacity $\mathbf{c}_{\mathbf{p}}$ resembles the calculated course. The complete course appears to be drifted over more than $300^{\circ} \mathrm{C}$ though. Therefore, the calculated course put down about $50 \mathrm{~J} / \mathrm{kgK}$ to approx. $590 \mathrm{~J} / \mathrm{kgK}$ so that it corresponds in the range up to $1,000^{\circ} \mathrm{C}$ with the mean average value indicated in [2]

The course of the fraction solid $\mathbf{f}_{\mathrm{s}}$ corresponds with the course calculated with Thermo-Calc. Merely a simple discontinuity was brought into line and the data set was kept otherwise.

The course of the Young's modulus $\mathbf{E}$ corresponded quantitatively with neither the literature nor the measurements carried out. Therefore, for the checked temperature range, the measured course was used and, except for $2,000^{\circ} \mathrm{C}$, extrapolated parallel to the behaviour of other alloys. For the solidified material, Young's modulus reaches approx. 100 to 180GPa.

The yield stress $\boldsymbol{\sigma}$ did not correspond with the available data set from the external sources nor with the measured data. So the course of the Young's modulus was measured according to [3] and extrapolated to $2,000^{\circ} \mathrm{C}$. The used upsetting limit $\mathrm{Rd}_{0.2}$ was raised so that the value amounts to approx. $1,000 \mathrm{MPa}$ at room temperature.

The Poisson's ratio $v$ lies according to all information between 0.31 and 0.33 , in dependence on the temperature. The idealized approach of a constant transverse contraction of 0.33 in the available data set was therefore maintained.

The course of the coefficient of thermal expansion $\boldsymbol{\alpha}$ in the available data set seems to rise unrealistically in the area of $1,000^{\circ} \mathrm{C}$. The mean average value was therefore set in accordance with [2] for the region up to $1,000^{\circ} \mathrm{C}$ since in this source, precisely the same alloy was examined. The upper temperature range was extrapolated and lies for this temperature outside the liquidus-lolidus interval at approximately $1.55^{*} 10^{-5} \mathrm{~K}^{-1}$.

The viscosity $\boldsymbol{\eta}$ of the available data set lies in a region equivalent to similar metal alloys and therefore was left unchanged for lack of other details.

As an additional data series for the consideration of the plastic deformation, the hardening-coefficient $\mathbf{n}$ must be fed into MAGMAsoft. This was fixed in dependence on available materials in the MAGMA database. For this the lower temperature range up to the brittle ductile transition glass and over the transition steel was taken as an archetype.

At first, the simulations of form filling, solidification and internal stresses with the new, improved data set were carried out in the already known conical full and hollow geometries for the purpose of comparability of the results.

The form filling simulation can be seen relatively independently to the further optimization of the solidification. This was restricted to a period of 5 seconds so that the changes regarding the cooling processes had no effect on this area of the simulation. To avoid a different cooling before reaching the shell mould, the heat transmission was reduced to a minimum between melt and environment up to the ingate so that the size of the furnace environment did not have influence on the form filling simulation either. The optimization of the air package was based on the previous results. It was the aim to bring the simulation into line with the real pouring results as far as possible. A criterion offering its services was the porosity of the cast components, which must be easy to judge with the naked eye with regard to its scale and distribution. Different furnace geometries were used to calculate the porosities. Since the porosities are between $7-10 \%$ in the complete sample, no colour gradations could be recognized in the simulation.

The attempt to use realisticy furnace geometry within MAGMAsoft and to copy only with the help of the heat transitions and the temperature of the heater the real cooling curve yielded no satisfactory results. This main reason was that merely a constant heater temperature at a time variable heat transmission could be defined for provision. The combination of the heat transitions to outer environment, furnace wall, the furnace air and the heater temperature are too complex to model a cooling curve in acceptable time. The solutions obtained showed either a too fast or slow cooling or the temperature distribution within the furnace was changed by proximity to the heater so that the temperature distribution over the complete furnace could not be seen any more as a plausible solution. In this case, if necessary, the heat conduction ought to have been adapted to the furnace atmosphere in addition. The strong temperature drop within the first half hours with a then constant temperature drop could not be copied since the iterative approach could not be practically converted due to the long simulation times. An automatically controlled variable customization with the cooling rate in single thermocouples as an optimization aim would be necessary or else a specific calculation of the heat transmissions at the heater for the obtainment the temperature demanded every time. The used technology shows complete results, however, to approach the furnace geometry only in its consequence.

Afterwards, sufficient geometry specification simulations of the residual stress were carried out. For the assessment of the tensions, the Mises reference stress was used here. This is valid only for the upper area above the brittle ductile transition, since a ductile material behaviour is presupposed. The results of the stress simulation were compared with the data set rearranged for the shell mould. Since this simulation of the reality gets closer, the maximum main tension and the maximum corresponding expansion are indicated here in addition to the comparable Mises tension. Both of the tolerable tensions lie above the resistance limit given at room temperature. The expansions lie partly around an order of magnitude above the elongation after fracture of the brittle material. As an additional criterion, a calculation of the warm crack inclination, which also provides information about possible cracks in the cast component besides the calculated stress distribution, was carried out in the context of the stress simulation. The solid specimen geometry was used for the simulations with CASTS. Combined solidification and stress simulations were carried out under certain boundary conditions. The results of the simulation under assumption of the real cooling curve for the surrounding air are represented in the following. Figure 9 shows the time-dependent situation of the solidus-liquidus interval for the assessment of the porosity inclination and for comparison purposes with the MAGMAsoft simulation.

\section{Simulation of the firmly bonded material composites}

The results of the real pouring tests for the fibre reinforcements were also confirmed by the simulation. The preform does not heat itself up during the filling stage. During solidification, the preform heated up to around the solidus temperature $\left(1,480^{\circ} \mathrm{C}\right)$ of the FG75 matrix. The liquidus temperature $\left(1,640^{\circ} \mathrm{C}\right)$ is reached only on the edge of the preforms, though. This means that by melting on the surface, a good connection is achieved between matrix and perform but simultaneously the preform can't completely melt on, which results in an increase of the properties of the material [9]. 


\section{Pouring development with numerical tools}

New geometries were simulated with the improved data set. Through this, it was possible to minimise the number of real pouring tests by initial choice of a suitable casting and ingate system. Furthermore, the crack avoidance was improved by the good correspondence between simulation and the reality and a good understanding of the process events was reached.

The simulation of the form filling shows an even, calm form filling at the specimen geometries for the examination of the core materials and the wall thickness minimization particularly in the area of the gating, Figure 10.

In the newly developed geometry of the production demonstrator, the main focus was on the form filling simulation for finding a suitable ingate system, Figure 11. Due to this, the low wall thicknesses after various variations has revealed that filling the demonstrator only from the head side in vertical form filling can be successful. The solidification simulation for this component shows that the temperature of the core and the perform reache the solidus temperature $1,480^{\circ} \mathrm{C}$ in the $\mathrm{FG} 75$ matrix, but has fallen below the liquidus temperature of $1,640^{\circ} \mathrm{C}$. Merely the edge of the preform melts-on which provides a good connection between matrix and preform. Figure 12 shows the temperature course in the matrix, the core and the preform directly after pouring.

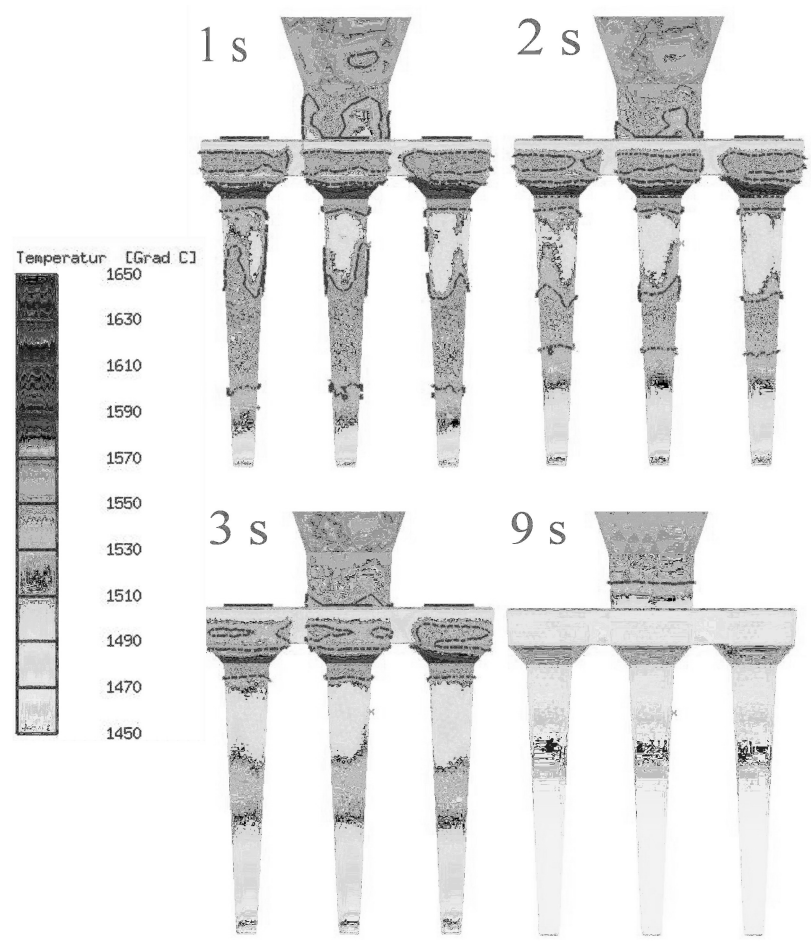

Figure 9: The figure shows the position of the liquidus-lolidus interval at the time steps of 1,2, 3 and 9s after the beginning of the simulation.

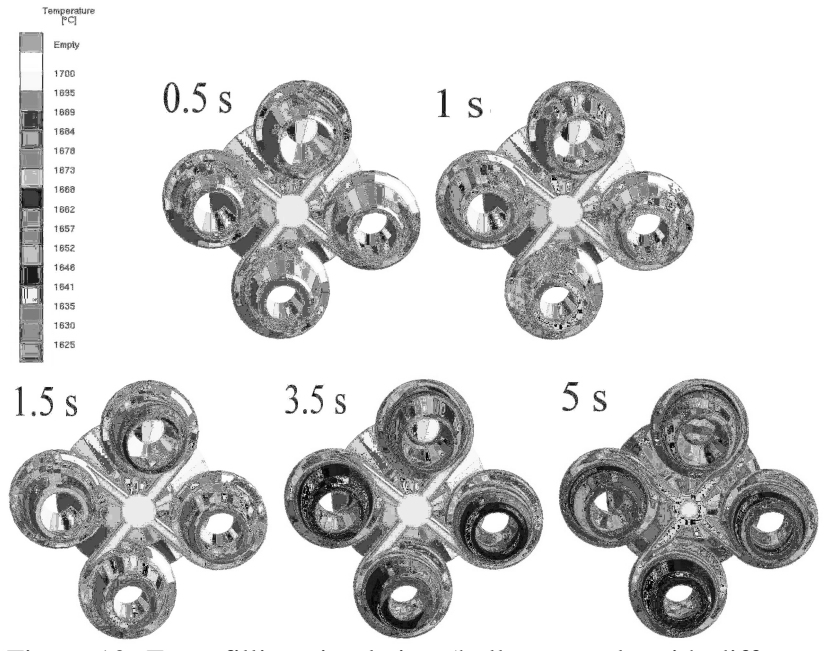

Figure 10: Form filling simulation (hollow sample with different wall thicknesses); angle of view from the rear side

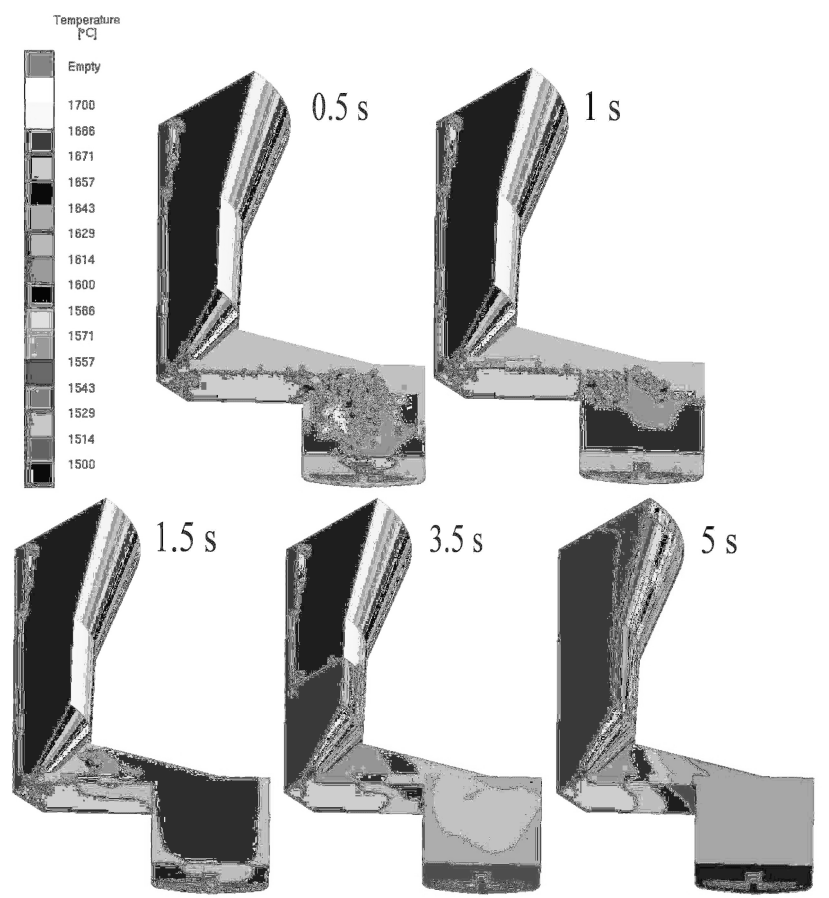

Figure 11: Simulation of the form filling (demonstrator)

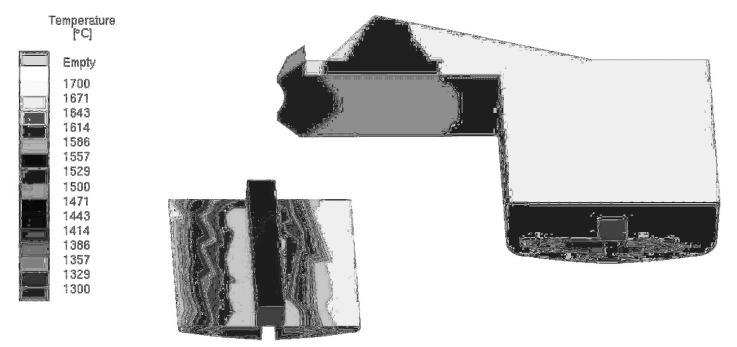

Figure 12: Simulation of the temperatures at the cores and the preform in comparison with the cast component after the pouring process. 


\section{Results}

In summary, it can be observed that the results are very promising for the current state of the NiAl investment casting research. There is an investment casting technology able to work for $\mathrm{NiAl}$ base alloys at the foundry institute which allows the pouring of more complex geometries with cavities, cores and long fibre reinforced preforms also in samples scaled more greatly. The most important results are listed in the following.

\section{Core materials}

At the foundry institute different, core materials for the pouring of $\mathrm{NiAl}$ are now available which are different in the core design. If a machining processing is possible for the geometry, the core material examined and used successfully can be applied. The range of application is, however, enlarged by the core materials developed in this period of the project. Due to the pourability of the concrete, almost complete geometry freedom is given for the core design. As most important requirements on the core material have to be named:

- $\mathrm{SiO}_{2}$ free,

- Heat resistance up to $=1800^{\circ} \mathrm{C}$,

- Compressive strength after the process of firing $<50 \mathrm{MPa}$,

- Minimal compressive strength after drying approx. 15$20 \mathrm{MPa}$.

The demands for $\mathrm{SiO}_{2}$ free and resistance to heat arise from the high reactivity of the melt and the process temperatures. In turn, a compressibility of the core material is required to avoid crack formation while pouring of hollow bodies and a minimal compressive strength guarantees a safe handling free from breakage of the fired cores after drying.

\section{Wall thicknesses}

The examination of the minimum possible wall thicknesses and the necessary technologies for this have delivered promising results. As Figure 1 indicates, wall thicknesses can also successfully be poured more thinly in combination with great cavities and with a high structure quality. Such geometry is in principle highly problematic due to shrinkage in the core. As a result of the examinations wall thicknesses, as follows can now be poured.

- Geometries without cavity of $1.5 \mathrm{~mm}$ wall thickness

- Hollow geometries of $4 \mathrm{~mm}$ wall thickness

- Hollow geometries at smaller measurements of $2 \mathrm{~mm}$ wall thickness

To ensure a filling at low wall thicknesses, the following pouring parameters must be adjusted:

- Pouring temperature $\mathrm{T}_{\mathrm{S}}: 1,700^{\circ} \mathrm{C} \pm 20^{\circ} \mathrm{C}$,

- Preheating temperature of the shell mould $\mathrm{T}_{\mathrm{F}}: 1,450^{\circ} \mathrm{C}$ (before $1300^{\circ} \mathrm{C}$ ) $\pm 5^{\circ} \mathrm{C}$

- Cooling rate above $1,100^{\circ} \mathrm{C}: 9 \mathrm{~K} / \mathrm{min}$,

- Cooling rate below $1,100^{\circ} \mathrm{C}: 2.5 \mathrm{~K} / \mathrm{min}$.

It is necessary to cause a smooth, undisturbed front layer on the shell mould production, as shown in Figure 3. Currently, further examinations are ongoing as an addition using hollow central geometries which can give way to a better extent to the shrinking casting. $\underline{\text { Possible geometries and dimensions }}$

There were three main problems to solve around upscaling of the samples relative to component sizes. For large components, complete filling must be guaranteed before solidification. This can be predicted excellently with the simulation tools now available and could be solved with this support well in theory and practice. Furthermore the problematic feeding behaviour of the alloy must be counteracted by suitable gating technology and feeders. This problem also can be mastered based on the numerical lay-outs in practice.

The problem of the dimensional stability was more difficult to solve. The very high preheating temperatures make the shell mould sodden. Consequently, it comes to an expanding of the shell mould as a result of the melt pressure. Reinforcements of the shell mould by increase of the backup layers do not represent a solution trial due to the crack formation that then appears. Suitable shell mould geometries can, however, prevent this expanding. In the case examined in the project, a simple support fulfils the aim.

\section{Fibre reinforcements of $\mathrm{NiAl}$}

After evaluation of the micrographs, a successful integration of $\mathrm{Al}_{2} \mathrm{O}_{3}$ long fibre reinforced preforms into cast components can be established. The high quality of the connection can be recognized in Figure 7. The following values are used as a procedure parameter:

- Pouring temperature $\mathrm{T}_{\mathrm{S}}: 1,700^{\circ} \mathrm{C} \pm 20^{\circ} \mathrm{C}$,

- Preheating temperature of the shell mould $\mathrm{T}_{\mathrm{F}}: 1,300^{\circ} \mathrm{C}$,

- Cooling rate above $1,100^{\circ} \mathrm{C}: 9 \mathrm{~K} / \mathrm{min}$,

- Cooling rate below $1,100^{\circ} \mathrm{C}: 2.5 \mathrm{~K} / \mathrm{min}$.

These are compatible with the process parameters for all further pouring experiments. The long fibre reinforcement of NiAl base alloys is therefore possible for this procedure method.

Turbine vane cut-out

The trail castings of the turbine blade cut-out were spilled, as described above, at the beginning without fibre preform and later with non-amplified FG75-core. The results altogether can be judged as very promising.

With sprue and gating geometries interpreted by means of simulations, form filling and feeding are unproblematic at all poured variants. The shell mould is filled completely and is roughly pore free. As well, the grain distribution in the component is smooth. This can be recognized well in the two right.hand micrograph images in Figure 14. The thin bar has run out completely and the component is largely pore free, Figure 13.

The connection to the fibre reinforced preforms also is successful. An enlarged micrograph image of the interface between fibre reinforced preform and the $\mathrm{NiAl}$ (FG75) can be seen on the left in Figure 14. The interface can barely be corresponded with the micrograph. The interface is free of pores and other disturbances. It must be said that a fibre reinforced preform was poured in worse quality in this case, though. Such preforms were mouldedin due to the costs and the lack of $\mathrm{Al}_{2} \mathrm{O}_{3}$ fibres along with that. Therefore the visible pores and infiltration defects of the fibre compound in the micrograph picture have no influence on the recasting experiments, though. The connection of the preforms is successful, and is in principle very good here, just like in the simple samples in the chapter "pouring technical production of long fibre reinforced $\mathrm{NiAl}$ components". 


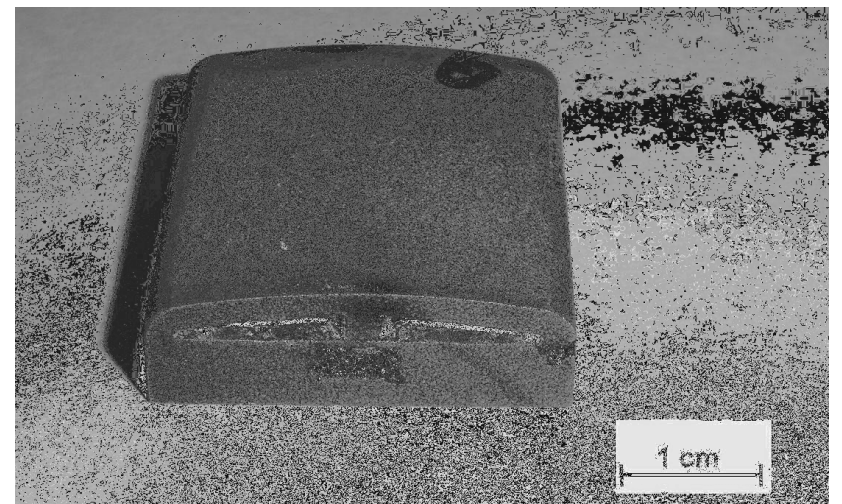

Figure 13: Sample of a turbine vane demonstrator with a long fibre reinforced core

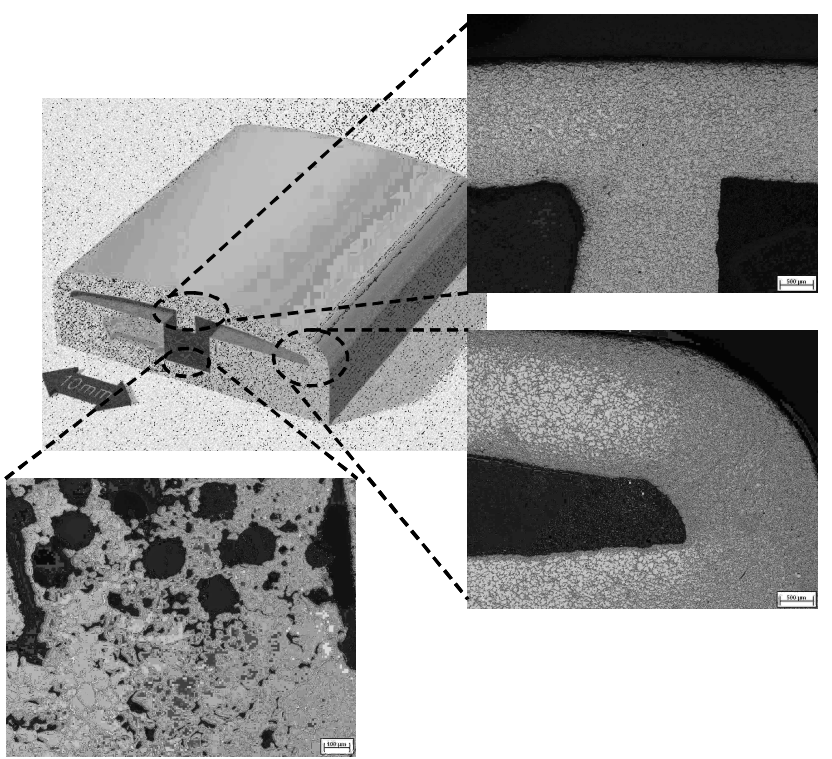

Figure 14: Micrograph pictures of the production demonstrator

\section{Summary and Conclusions}

1. The core material 1801 fulfils the necessary requirements for the NiAl investment casting of FG75. The material combines qualities like absence of $\mathrm{SiO}_{2}$, chemical resistance, heat resistance as well as the compressive strength after firing of $<50 \mathrm{MPa}$.

2. Starting out from little plate-shaped samples, more complex, hollow components and finally cut-out parts of turbine blades and large $\mathrm{NiAl}$ samples were cast.

3. The fibre reinforcement of $\mathrm{NiAl}$ components was realized using the process demonstrator. Furthermore, use of investment casting cores for $\mathrm{NiAl}$, the representation of thin wall thicknesses to $2 \mathrm{~mm}$ and possibility of varying wall thicknesses within a component was shown at the demonstrator.

4. During the work carried out a comprehensive data set was worked out by modification and further development of the existing data for FG75. Simulations could be used for the improvement in the pouring tests successfully basing this one on this data set numeric.

\section{References}

[1] H. Rothe: „Untersuchungen der Rißbildungen bei der Herstellung keramischer Formschalen“, Shaker Verlag, Band 11, Aachen, 1999

[2] Sauthoff, G.: „Multiphase intermetallic alloys for structural applications."

In: Intermetallics 8 (2000), S. 1101-1109

[3] Sauthoff, G., Frommeyer, G., Palm, M.: „Intermetallic NiAl-components for systems for ecologically friendly Energy conversion, Subproject material characterization and optimization, work package A1: NiAl-Ta-Cr-alloys / Max-PlanckInstitut für Eisenforschung GmbH. 2001. -Research Report

[4] Scheppe, F.: Foundry-Institute: Research, Development, Results. Volume 27: „Investment Casting Technology for NiAlbase-alloys“, Shaker Publisher, 2001

[5] M.Rosefort, C.Dahmen, A.Bührig-Polaczek: "Feinguss effusionsgekühlter NiAl-Gasturbinenschaufeln: Prozessentwicklung mittels numerischer Simulation", Werkstoffwoche 2004, München, 2004

[6] M. Rosefort, M. Fehlbier, A. Bührig-Polaczek: „NiAl Material for the Application in Gas Turbines -“, Zeitschrift für Metallkunde, 12/2004, Carl Hanser Verlag GmbH \& Co.KG, München

[7] M.Rosefort, C.Dahmen, A.Bührig-Polaczek: „Composite Casting of the Intermetallic Phase NiAl“, Proc. ICCE 12, Tenerife, 2005

[8] C. Dahmen, M. Rosefort, A. Bührig-Polaczek: „Verbundguss der intermetallischen Phase NiAl“, Proc. Verbundwerkstoffe 2005, Kassel, 2005,

[9] M.Rosefort, C.Dahmen, A.Bührig-Polaczek, W.Hu G.Gottstein, D.Hajas, J.M.Schneider: "Longfibre Reinforced NiAl: High Temperature Material for Turbine Blades", Advanced Engeneering Materials, 2006, 8, No.8, S.730-735

[10] M. Rosefort., C.Dahmen, A. Bührig-Polaczek: ", Verbundkonzepte zum Einsatz von hochtemperaturfestem NiAl ", Verbundwerkstoffe und Werkstoffverbunde 2007, Bremen, 2007, eingereicht 